\title{
Flexural Strength of Temporary Restorative Materials Stored in Different Solutions
}

\author{
Nuran Dinçkal Yanikoğlu1, Funda Bayindir¹, Duygu Kürklü1, Bilge Beşir² \\ ${ }^{1}$ Prosthodontics Department, Faculty of Dentistry, Atatürk University, Erzurum, Turkey \\ ${ }^{2}$ Prosthodontics Department, Faculty of Dentistry, Karadeniz Teknik University, Trabzon, Turkey \\ Email: nyanikoglu@gmail.com
}

Received 26 April 2014; revised 30 May 2014; accepted 7 June 2014

Copyright (C) 2014 by authors and Scientific Research Publishing Inc.

This work is licensed under the Creative Commons Attribution International License (CC BY).

http://creativecommons.org/licenses/by/4.0/

(c) (i) Open Access

\begin{abstract}
Aim: The aim of this study was to evaluate the effects of different solutions on the flexural strength of one methacrylate-based resin and three bis-acryl resin provisional materials using an in vitro model test system. Methods: The specimens $(25 \times 2 \times 2 \mathrm{~mm})$ were prepared from interim materials and stored for 14 days at $37^{\circ} \mathrm{C}$ in different solutions (coffee, burn, cola) and distilled water (control group). A standard three-point bending test was conducted on the specimens with an Instron universal testing machine at crosshead speed of $0.5 \mathrm{~mm} / \mathrm{min}$. Data were analyzed using the one-way analysis of variance and Tukey HSD multiple comprasion tests. Results: The methacrylate-based resin (Takilon) showed the least fracture strength $(61.6$ - 85.6 MPa). One of the bis-acryl resins (Protemp 4-3M ESPE) showed the highest fracture strength (112 - $128 \mathrm{MPa})$. Conclusions: All bis-acryl resin composite materials exhibited high fracture strength over the traditional methyl methacrylate resin throughout the 14 day time interval of investigation. The different solutions have not statistically significant effect on the flexure strength values on four temporary materials.
\end{abstract}

\section{Keywords}

Component, Temporary Dental Restorations, Acrylic Resins, Dental Resins

\section{Introduction}

Provisionalization of fixed restorations is an essential part of the treatment before placement of the final restorations. The immediate protective, functional, and stabilizing value of interim restorations are useful for diagnostic purposes where the functional, occlusal, and esthetic parameters are developed to identify an optimum treatment outcome before the completion of definitive procedures [1] [2]. 
Provisional materials generally exhibit low fracture strengths, particularly when the patient must use the provisional restoration for an extended period, when the patient have parafunctional habits, or when a long-span prosthesis is planned [3]. Resistance to functional load and removal forces which are mechanical factors must be considered when choosing a provisional restorative material for clinical use [4]. Provisional restorations are fabricated using resin based provisional crown and bridge materials [5]. Interim fixed restorative materials can be divided into four groups according to composition: polymethyl methacrylate (PMMA), polyethyl or butyl methacrylate, microfilled bisphenol A-glycidyl dimethacrylate (Bis-GMA) composite resin, and urethane dimethacrylate (light-polymerizing resins) [6] [7]. While ethyl methacrylates have poor aesthetics and wear resistance, methyl methacrylates and bis-acryl resin composites are superior with regard to those properties [8] [9].

Conventional methacrylate resins are monofunctional, low molecular weight, linear molecules that exhibit decreased strength and rigidity. In addition, if they are not polymerized under pressure, the air bubbles will be trapped and decrease their strength [10]-[12]. The primary monomer determines many of the material characteristics such as polymerization shrinkage, strength, and exothermic heat of reaction [6]. PMMA resin has a relatively poor resistance to stress under impact, bending, and fatigue modes [13]. Previous studies have evaluated the marginal fit, polymerization shrinkage, periodontal response, temperature rise, color stability, and fracture resistance of various provisional materials. Presently, there is no provisional material that meets optimal requirements for all situations [14]. Clinicians typically choose a product based on the ease of manipulation, aesthetics, and cost [15]. Autopolymerizing acrylic resin is usually the biomaterial for provisional restorations. However, when long-term provisional fixed restorations replace several teeth, the strength and stability of the prosthesis is critical [16].

In recent years, the composite-based temporary crown and bridge materials have gained popularity among dental practitioners. Besides advantages regarding the handling versus traditional powder-liquid systems, superior mechanical properties might be an explanation for this market trend [11] [14] [17] [18]. A temporary restoration is mostly fabricated directly chair-side, consequently the restoration is fitted immediately after fabrication. From practical experience, this procedure takes no longer than 10 - 30 min after the end of mixing [19].

The fracture strength of a provisional crown and bridge material is of particular importance, as this factor might influence the integrity of the provisional restoration during its time in situ (1 - 2 weeks up to several months) [3] [11] [20]. The mechanical properties of the provisional materials can be influenced by saliva, food components, beverages, and interactions among these materials in the oral environment [21]-[24]. Therefore, their integrity must be preserved throughout the treatment period.

The flexural strength of interim prostheses is a critical property, particularly in long-span interim prostheses with short height pontics and connectors [6] and when the patient exhibits parafunctional habits such as bruxism and clenching. Flexural strength is also important when these restorations are worn over a long period of time to assess the results of periodontal, endodontic, and temporomandibular joint dysfunction therapies and during the restorative phase of implant reconstructive procedures [11] [17] [25]-[28].

The aim of this study was to investigate the effects of different solutions (cola, coffee, energy drink and distilled water) on the flexural strength of four (one methacrylate-based resin and three bis-acryl resin) provisional restorative materials.

\section{Material and Methods}

Table 1 lists the brand names and contents of the four provisional restorative materials used in this study. The specimens were fabricated according to ADA specification \#27 $(25 \times 2 \times 2 \mathrm{~mm})$ [29]. The provisional restorative materials were mixed according to manufacturers' instructions and injected into silicon molds. After the polymerization time recommended by the manufacturer, they were examined visually for the presence of air bubbles, and defective specimens were excluded from the study. The specimens (X80) were then randomly divided into test groups each consisting of 5 specimens. The materials were stored for 14 days at $37^{\circ} \mathrm{C}$ in three different solutions coffee (Unsweetened Nescafe Classic), energy drink (Burn), cola (Coca-cola) and distilled water (control group). At the end of the conditioning period, the specimens were washed under running water and air-dried. A standard three-point bending test was conducted on the specimens with an Autograph Ag-Is testing machine (Shımadzu, Tokyo, Japan) at a crosshead speed of $0.5 \mathrm{~mm} /$ minute. Maximal loads to fracture in Newton were recorded. 
Table 1. Materials used in this study.

\begin{tabular}{cccc}
\hline & Manufacturer & Composition type & Lot number \\
\hline Protemp 4 & 3M-ESPE,Seefeld,Germany (autopolymerized) & Bis-Acrylic Composite & 9022 \\
Structur 2SC & VOCO America, Inc. (autopolymerized) & Bis-Acrylic Composite \\
Access Crown & Centrixinc.,Unitedstates (autopolymerized) & Bis-Acrylic Composite & 0938052 \\
Takilon & Varpa Ltd. (autopolymerized) & Methylmethacrylate & 8767 \\
\hline
\end{tabular}

\section{Statistical Analysis}

The mean values of fracture strength of each provisional material was calculated in MPa. Datas were analyzed using the one-way analysis of variance (ANOVA), Tukey HSD multiple comprasion tests, and the significance level was set at $\alpha=0.05$.

\section{Results}

The mean values and standard deviations of the four provisional materials are shown in Table 2. Mean fracture strengths ranged from 61.6 to $128 \mathrm{MPa}$. The different solutions did not have a statistically significant effect on the fracture strength of the four provisional materials investigated ( $p>0.05)$. The methacrylate-based resin (Takilon) which was stored in coffee showed the lowest fracture strength (61.6 MPa). One of the bis-acrylic resins (Protemp 4, 3M-ESPE) showed the highest fracture strength (128 MPa) in Cola for 14 days (Figure 1).

\section{Discussion}

The mechanical stability of temporary crown and bridge materials is important to prevent failure of a temporary restoration directly from the beginning after fabrication and insertion. However, very little information available on this subject in the current literature [19]. A good provisional restoration should satisfy the following requirements: pulpal protection, positional stability, ease in cleaning, accurate margins, strong, wear resistant, dimensional stability, and serve as a diagnostic aid in treatment assessment and esthetics [9].

Although laboratory flexural strength values under static loading may not reflect intraoral behaviour, these values are nevertheless helpful in comparing materials under controlled situations and may be a useful predictor of clinical performance [18].

In the oral environment, it can be assumed that saliva, food components, beverages and interactions among these materials can degrade and age dental restorations [21]. Wu et al. [30] and Assmussen [31] reported that the resin matrices of dental composites become softened with exposure to organic acids and to various food and liquid constituents. In addition, when composites are soaked in oral fluids, disintegration at the resin-filler interface occurs [32], Therefore, the chemical environment in the oral cavity may have a critical influence on the in vivo degradation of composite resins [21]. There are several further reports [33]-[36] which have investigated the effects of food-simulating liquids on the mechanical properties of dental composites; however, to date, the effects of these agents on the mechanical properties of the provisional restorative materials have been tested in only one study [36].

Akova et al. [21] suggested that the flexural strength and hardness of provisional restorative materials are influenced by the food-simulating solutions in vitro. Yap et al. [36] reported that bis-acryl resin composite materials are generally softer than methylmethacrylate and urethane methacrylate materials, which are more resistant to the degradatory effects of dietary simulating solvents.

Nejatidanesh et al. [37] studied the flexural strenght of interim resin materials stored in artificial saliva and thermocycled for 2500 cycles between $5^{\circ} \mathrm{C}$ and $55^{\circ} \mathrm{C}$. They concluded that bis-acryl interim materials were exhibited higher flexural strength than the monomethacrylate resins for interim prostheses, and these higher values should be considered when making interim fixed prostheses, especially when planning long-term use or long-span fixed prosthesis.

Balkenhola et al. [38] stated that the fracture toughness of biomaterials for temporary restorations depends on the storage time as well as the material. As the storage time increased (up to 7 days storage in water), the two dimethacrylates Luxatemp AM Plus and Protemp 3 Garant exhibited higher fracture toughness values which 
Table 2. The mean and standard deviation of the materials in different solutions (MPa).

\begin{tabular}{ccccc}
\hline $\begin{array}{c}\text { Materials } \\
\text { Solutions }\end{array}$ & Takilon & Protemp 4 & Structur 2 SC & Access \\
\hline Distilled water & $69,0^{\mathrm{a}}$ & $122,0^{\mathrm{c}}$ & $119,0^{\mathrm{c}}$ & $110,0^{\mathrm{bc}}$ \\
Cola & $68,6^{\mathrm{a}}$ & $\mathbf{1 2 8 , 0 ^ { \mathrm { c } }}$ & $105,0^{\mathrm{bc}}$ & $126,0^{\mathrm{c}}$ \\
Coffee & $\mathbf{6 1 , 6 ^ { \mathrm { a } }}$ & $120,0^{\mathrm{c}}$ & $105,0^{\mathrm{bc}}$ & $114,0^{\mathrm{bc}}$ \\
Energy drink & $85,6^{\mathrm{b}}$ & $112,0^{\mathrm{bc}}$ & $112,0^{\mathrm{bc}}$ & $118,0^{\mathrm{bc}}$ \\
\hline
\end{tabular}

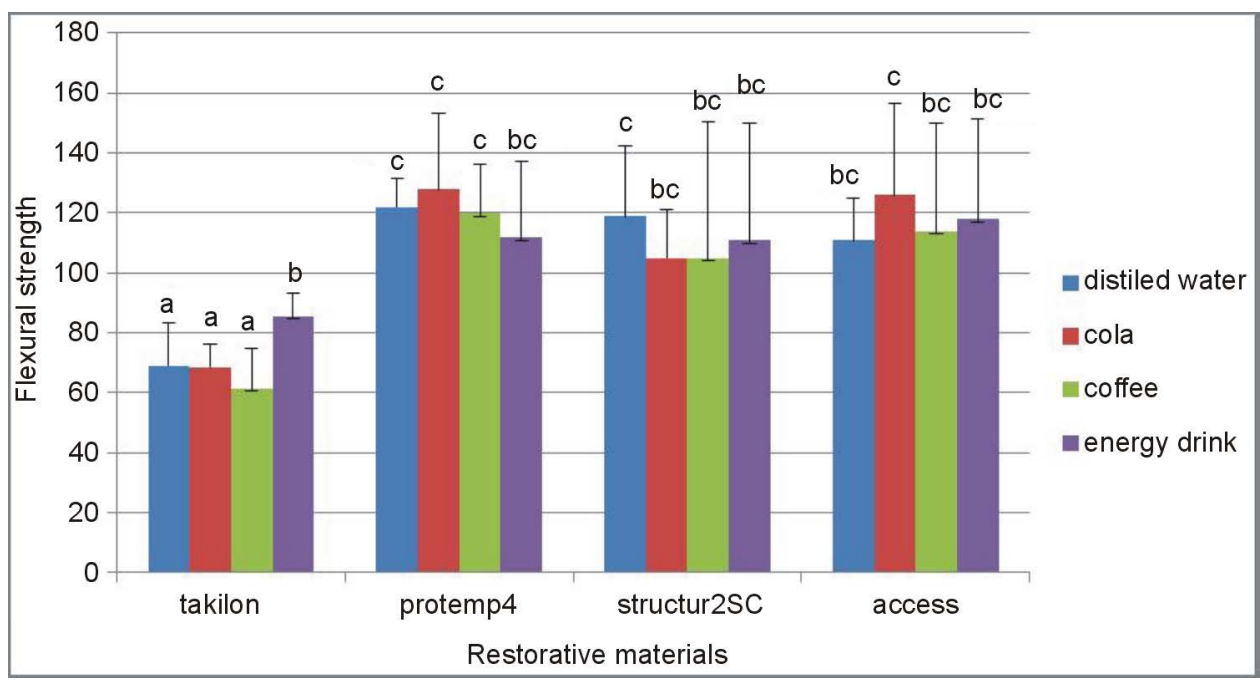

Figure 1. Mean and standard deviations of temporary restorative materials after storage in different solutions for 14 days.

then decreased under the influence of thermocycling. Similar tendencies after prolonged water storage are also reported in other investigations for various composites [39]-[42]. Diaz-Arnold et al. [12] suggested that the hardness of most materials (Integrity, Protemp Garant, Jet) decreased over time. All of the bis-acryl resin composite materials exhibited superior microhardness over traditional methyl methacrylate (Jet, Temporary Bridge) resins.

Akova et al. [21] stated that, the specimens were conditioned in the food simulating liquids (FSL) for 1 week before the tests. This period may be considered long, since the restoratives come into contact with foods and beverages only during eating and drinking until teeth are cleaned; however, these chemical agents can be trapped around the margins and connectors of inadequately fabricated/finished provisional prostheses, and into porosities of poorly manipulated materials. Lang et al. [18] investigated fracture resistance of interim fixed partial denture materials after storage for 14 days in distilled water and artificial aging and found low mechanical fracture behavior and total failure of PMMA materials tested because of deformation during oral simulation. They also found that PMMA materials showed water absorption up to $32 \mu \mathrm{g} / \mathrm{mm}$, primarily because of the polar properties of the resin molecules, which may act as a plasticizer and thus reduce the fracture strength of the materials.

In the present study, specimens were stored for 14 days in different solutions (coffee was unsweetened, cola was Coca-cola and energy drink was Burn) and distilled water (control group) to partially simulate the oral environment. The results of this study indicated that the different solutions tested did not have a statistically significant effect on the fracture strength of provisional materials, although bis-acryl composite resin materials had the highest flexural strength, and methacrylate resin exhibited the lowest. This result is consistent with those of past studies in which the flexural strength of bis-acryl resins was higher than other conventional interim restorative materials [10] [11] [18] [21] [43]. The fracture resistance of interim materials is subject to the geometry of the restoration and aging processes that occur in clinical application [21]-[24].

Haselton et al. [11] compared flexural strength of methacrylate base resins and bis-acryl resins after immersing in artificial saliva for 10 days. Results showed that some, but not all, bis-acryl resins demonstrated signifi- 
cant superior flexural strength than traditional methacrylate resins. They concluded that the differences in flexural strength can be partly attributed to differences in chemical compositions; however, they deemed this property to be material specific. The differences between flexural strength of methacrylate resins and bis-acryl resins are a result of the different monomer composition. The bis-acryl resins contain multifunctional monomers, which increase the strength due to cross-linking with other monomers.

Balkenhol et al. [44] studied the flexural strength and flexural modulus of interim resin materials at different storage times and concluded that the mechanical properties of composite resin-based materials are superior to methacrylate resins and recommended a dual-curing interim resin material if a high mechanical strength is indispensable directly after fabrication. They explained that in dual-curing materials a large amount of polymerization takes place at the beginning because of the light curing initiation of the reaction.

Balkenhol et al. [44] stated that composite resin based materials are preferred versus methacrylate resins due to more favourable mechanical properties. If a high mechanical strength is indispensable directly after fabrication, a dual-curing provisional material is recommended.

The edge-strength of a polymer-based provisional material could be an important factor to be taken into account in selecting suitable materials for clinical use. These findings show that the monomethacrylate-based provisional restorations would be expected to be more susceptible to mechanical failure and less durable than the dimethacrylate-based provisional restorations when they are exposed to heavy masticatory stresses [45].

Poonacha et al. [46] stated that Methacrylate based autopolymerizing resins showed the highest flexural strength and elastic moduli after fabrication and after storing in artificial saliva and for 24 hours and 7 days and Bis-acrylic composite resin showed the least flexural strength and elastic moduli.

Gujjari et al. [47] reported that material based on PMMA was more resistant to damage from dietary beverages as compared to bis-acrylic composite based provisional crown and bridge resin.

Zortuk et al. [48] reported that, Temdent which contains only methyl methacrylate, was the most resistant to pressure-induced fracture and Protemp, which contains BIS-GMA, was the least resistant.

There was no significant difference between methylmethacrylate and composite interim materials in some of the studies [49]-[51]. This can be explained by the difference in the test method and materials. In some studies, the size of specimens was different, and an early generation of composites was used [50] [51].

Direct comparison to other studies [4] [10] [11] [17] [36] [37] was not possible due to differences in materials, methodology, and specimen configuration.

Starting points for cracks are microscopically small defects in or just beneath the surface of the material created during trimming and polishing [42] [52] or encountered in the oral cavity while the restoration is in situ-due to the masticatory loads [30] [52]-[55].

It should be mentioned that flexural strength is only one of a number of factors influencing the success of an interim prosthesis. A strong material may possess other less desirable characteristics. For example, a restorative material may be difficult to manipulate, have tendency to stain easily, lack polishability, or not be esthetically pleasing [11]. There are no published studies regarding exactly which measured mechanical properties may best aid the clinician in predicting in vivo performance of provisional restorative materials [10].

The clinician must be aware of all attributes of various materials and choose the interim material appropriate for each patient [37].

\section{Conclusion}

Within the limitations of this study, it may be concluded that the flexural strength of provisional restorative materials are not signifcantly influenced by storage in different solutions. Bis-acryl provisional materials exhibited higher flexural strength than the methacrylate resins.

\section{Acknowledgements}

Thanks for material support to Dt. Beril Balci, 3M ESPE/Turkey. 34th Annual Conference of the European Prosthodontic Association and 1st Conference of the Association of prosthetic Dentistry of Kosova, in September 23-25/2010 Prishtina/Kosova.

\section{References}

[1] Lowe, R.A. (1987) The Art and Science of Provisionalization. The International Journal of Periodontics \& Restorative 
Dentistry, 7, 64-73.

[2] Baldissara, P., et al. (1998) Comparative Study of the Marginal Microleakage of Six Cements in Fixed Provisional Crowns. Journal of Prosthetic Dentistry, 80, 417-422. http://dx.doi.org/10.1016/S0022-3913(98)70005-8

[3] Rosenstiel, S.F. (2001) Contemporary Fixed Prosthodontics. 3rd Edition, Vol. Mosby-Yearbook, St. Louis Missouri, 380 .

[4] Zuccari, A.G., et al. (1997) Reinforcement of Acrylic Resins for Provisional Fixed Restorations. Part II: Changes in Mechanical Properties as a Function of Time and Physical Properties. Bio-Medical Materials and Engineering, 7, 345-355.

[5] Burns, D.R., Beck, D.A. and Nelson, S.K. (2003) A Review of Selected Dental Literature on Contemporary Provisional Fixed Prosthodontic Treatment: Report of the Committee on Research in Fixed Prosthodontics of the Academy of Fixed Prosthodontics. Journal of Prosthetic Dentistry, 90, 474-497. http://dx.doi.org/10.1016/S0022-3913(98)70005-8

[6] Rosenstiel, S.F., Land, M.F. and Fujimoto, J. (2006) Contemporary Fixed Prosthodontics. 4th Edition, St. Louis, Mosby, 96, 466-479.

[7] Nejatidanesh, F., Lotfi, H.R. and Savabi, O. (2006) Marginal Accuracy of Interim Restorations Fabricated from Four Interim Autopolymerizing Resins. Journal of Prosthetic Dentistry, 95, 364-367. http://dx.doi.org/10.1016/j.prosdent.2006.02.030

[8] Krug, R.S. (1975) Temporary Resin Crown and Bridges. Dental Clinics of North America, 19, 313-320.

[9] Shillinburg, H.T., Hobo, S., Whitsett, L.D., Jacobi, R. and Brackett, S.E. (1997) Provisional Restorations. Fundamentals of Fixed Prosthodontics. 3rd Edition, Quintessence Publishing Co. Inc., Illinois, 225-257.

[10] Ireland, M.F., Dixon, D.L., Breeding, L.C., et al. (1998) In Vitro Mechanical Property Comparison of Four Resins Used for Fabrication of Provisional Fixed Restorations. Journal of Prosthetic Dentistry, 80, 158-162. http://dx.doi.org/10.1016/S0022-3913(98)70104-0

[11] Haselton, D.R., Diaz-Arnold, A.M. and Vargas, M.A. (2002) Flexural Strength of Provisional Crown and Fixed Partial Denture Resins. Journal of Prosthetic Dentistry, 87, 225-228. http://dx.doi.org/10.1067/mpr.2002.121406

[12] Diaz-Arnold, A.M., Dunne, J.T. and Jones, A.H. (1999) Microhardness of Provisional Fixed Prosthodontic Materials. Journal of Prosthetic Dentistry, 82, 525-28. http://dx.doi.org/10.1016/S0022-3913(99)70050-8

[13] Grave, A.M., Chandler, H.D. and Wolfaardt, J.F. (1985) Denture Base Acrylic Reinforced with High Modulus Fibre. Dental Materials, 1, 185-187. http://dx.doi.org/10.1016/S0022-3913(99)70050-8

[14] Young, H.M., Smith, C.T. and Morton, D. (2001) Comparative in Vitro Evaluation of Two Provisional Restorative Materials. Journal of Prosthetic Dentistry, 85, 129-132. http://dx.doi.org/10.1067/mpr.2001.112797

[15] Allen, E., Bayne, S., Donovan, T., Hansson, T., Klooster, J. and Kois, J. (1996) Annual Review of Selected Dental Literature. Journal of Prosthetic Dentistry, 76, 56-93. http://dx.doi.org/10.1016/S0022-3913(96)90347-9

[16] Galindo, D., Soltys, J.L. and Graser, G.N. (1998) Long-Term Reinforced Fixed Provisional Restorations. Journal of Prosthetic Dentistry, 79, 698-701. http://dx.doi.org/10.1016/S0022-3913(98)70078-2

[17] Ireland, M.F., Dixon, D.L., Breeding, L.C. and Ramp, M.H. (1998) In Vitro Mechanical Property Comparison of Four Resins Used for Fabrication of Provisional Fixed Restorations. Journal of Prosthetic Dentistry, 80, 158-162. http://dx.doi.org/10.1016/S0022-3913(98)70104-0

[18] Lang, R., Rosentritt, M., Behr, M. and Handel, G. (2003) Fracture Resistance of PMMA and Resin Matrix CompositeBased Interim FPD Materials. The International Journal of Prosthodontics, 16, 381-384.

[19] Balkenhol, M., Ferger, P., Mautner, M.C. and Wöstmann, B. (2007) Provisional Crown and Fixed Partial Denture Materials: Mechanical Properties and Degree of Conversion. Dental Materials, 23, 1574-1583. http://dx.doi.org/10.1016/j.dental.2007.06.024

[20] Craig (2006) Craig’s Restorative Dental Materials. Mosby Elsevier, St. Louis.

[21] Akova, T., Ozkomur, A., and Uysal, H. (2006) Effect of Food-Simulating Liquids on the Mechanical Properties of Provisional Restorative Materials. Dental Materials, 22, 1130-1134. http://dx.doi.org/10.1016/j.dental.2005.09.009

[22] Soderholm, K.J. and Roberts, M.J. (1990) Influence of Water Exposure on the Tensile Strength of Composites. Journal of Dental Research, 69, 1812-1816. http://dx.doi.org/10.1177/00220345900690120501

[23] Lee, S.Y., Greener, E.H., Mueller, H.J. and Chiu, C.H. (1994) Effect of Food and Oral Simulating Fluids on Dentine Bond and Composite Strength. Journal of Dentistry, 22, 352-359. http://dx.doi.org/10.1016/0300-5712(94)90088-4

[24] Oshida, Y., Hashem, A. and ElSalawy, R. (1995) Some Mechanistic Observation on Water-Deteriorated Dental Composite Resins. Bio-Medical Materials and Engineering, 93, 115.

[25] Bichacho, N. and Landsberg, C.J. (1997) Single Implant Restorations: Prosthetically Induced Soft Tissue Topography. Pract Periodontics Aesthet Dent, 9, 745-752. 
[26] Stein, J.M. and Nevins, M. (1996) The Relationship of the Guided Gingival Frame to the Provisional Crown for a Single-Implant Restoration. Compendium of Continuing Education in Dentistry, 17, 1175-1182.

[27] Jemt, T. (1999) Restoring the Gingival Contour by Means of Provisional Resin Crowns after Single-Implant Treatment. The International Journal of Periodontics and Restorative, 19, 20-29

[28] Savabi, O. and NejatiDanesh, F. (2003) A Method for Fabrication of Temporary Restoration on Solid Abutment of ITI Implants. Journal of Prosthetic Dentistry, 89, 419. http://dx.doi.org/10.1067/mpr.2003.79

[29] ANSI/ADA Specification No. 27, Direct Filling Resins. American National Standards Institute, a.D.A.R.

[30] Wu, W., Toth, E.E., Moffa, J.F. and Ellison, J.A. (1984) Materials Science Subsurface Damage Layer of in Vivo Worn Dental Composite Restorations. Journal of Dental Research, 63, 675-680. http://jdr.sagepub.com/content/63/5/675 http://dx.doi.org/10.1177/00220345840630051401

[31] Assmussen, E. (1984) Softening of BIS-GMA Based Polymers by Ethanol and by Organic Acids of Plaque. Scandinavian Journal of Dental Research Odontologist, 92, 257-261.

[32] Roulet, J.F. and Walti, C. (1984) Influence of Oral Fluid on Composite Resin and Glass-Ionomer Cement. The Journal of Prosthetic Dentistry, 52, 182-189. http://dx.doi.org/10.1016/0022-3913(84)90092-1

[33] Yap, A.U.J., Tan, D.T.T., Goh, B.K.C., Kuah, H.G. and Goh, M. (2000) Effects of Food-Simulating Liquids on the Flexural Strength of Composite and Poly-Acid Modified Composite Restoratives. Operative Dentistry, 25, 202-208.

[34] Yap, A.U.J., Low, J.S. and Ong, L.F.K.L. (2000) Effects of Food-Simulating Liquids on Surface Characteristics of Composite and Poly-Acid Modified Composite Restoratives. Operative Dentistry, 25, 170-176.

[35] Yap, A.U.J., Le, M.K., Chung, S.M., Tsai, K.T. and Lim, C.T. (2003) Effects of Food-Simulating Liquids on the Shear Punch Strength of Composite and Poly-Acid Modified Composite Restoratives. Operative Dentistry, 28, 529-534.

[36] Yap, A.U.J., Mah, M.K.S., Lye, C.P.W. and Loh, P.L. (2004) Influence of Dietary Simulating Solvents on the Hardness of Provisional Restorative Materials. Dental Materials, 20, 370-376. http://dx.doi.org/10.1016/j.dental.2003.06.001

[37] Nejatidanesh, F., Momeni, G. and Savabi, O. (2009) Flexural Strength of Interim Resin Materials for Fixed Prosthodontics. Journal of Prosthodontics, 18, 507-511. http://dx.doi.org/10.1111/j.1532-849X.2009.00473.x

[38] Balkenhola, M., Köhlerb, H., Orbacha, K. and Wöstmanna, B. (2009) Fracture Toughness of Cross-Linked and NonCross-Linked Temporary Crown and Fixed Partial Denture Materials. Dental Materials, 25, 917-928. http://dx.doi.org/10.1016/j.dental.2009.01.099

[39] Ferracane, J.L., Hopkin, J.K. and Condon, J.R. (1995) Properties of Heat-Treated Composites after Aging in Water. Dental Materials, 11, 354-358. http://dx.doi.org/10.1016/0109-5641(95)80034-4

[40] Pilliar, R.M., Smith, D.C. and Maric, B. (1986) Fracture Toughness of Dental Composites Determined Using the Short-Rod Fracture Toughness Test. Journal of Dental Research, 65, 1308-1314. http://dx.doi.org/10.1177/00220345860650110501

[41] Kim, S.H. and Watts, D.C. (2004) Effect of Glass-Fiber Reinforcement and Water Storage on Fracture Toughness (KIC) of Polymer-Based Provisional Crown and FPD Materials. The International Journal of Prosthodontics, 17, 318-322.

[42] Lloyd, C.H. and Adamson, M. (1987) The Development of Fracture Toughness and Fracture Strength in Posterior Restorative Materials. Dental Materials, 3, 225-231. http://dx.doi.org/10.1016/S0109-5641(87)80077-5

[43] Kao, E.C. (1989) Influence of Food-Simulating Solvents on Resin Composites and Glass-Ionomer Restorative Cement. Dental Materials, 5, 201-208. http://dx.doi.org/10.1016/0109-5641(89)90014-6

[44] Balkenhol, M., Mautner, M.C., Ferger, P. and Wöstmann, B. (2008) Mechanical Properties of Provisional Crown and Bridge Materials: Chemical-Curing versus Dual-Curing Systems. Journal of Dentistry, 36, 15-20. http://dx.doi.org/10.1016/j.jdent.2007.10.001

[45] Kim, S.H. and Watts, D.C. (2007) In Vitro Study of Edge-Strength of Provisional Polymer-Based Crown and Fixed Partial Denture Materials. Dental Materials, 23, 1570-1573. http://dx.doi.org/10.1016/j.dental.2007.06.023

[46] Poonacha, V., Poonacha, S., Salagundi, B., Rupesh, P.L. and Raghavan, R. (2013) In Vitro Comparison of Flexural Strength and Elastic Modulus of Three Provisional Crown Materials Used in Fixed Prosthodontics. Journal of Clinical and Experimental Dentistry, 5, 212-217. http://dx.doi.org/10.4317/jced.51136

[47] Gujjari, A.K., Bhatnagar, V.M. and Basavaraju, R.M. (2013) Color Stability and Flexural Strength of Poly (Methyl Methacrylate) and Bis-Acrylic Composite Based Provisional Crown and Bridge Auto-Polymerizing Resins Exposed to Beverages and Food Dye: An in Vitro Study. Indian Journal of Dental Research, 24, 172-177.

[48] Zortuk, M., Ozdemir, E. and Aguloglu, S. (2010) Evaluating the Fracture Strength of Three Different Provisional Crowns. Journal of International Dental and Medical Research, 3, 25-28 
[49] Koumjian, J.H. and Nimmo, A. (1990) Evaluation of Fracture Resistance of Resins Used for Provisional Restorations. The Journal of Prosthetic Dentistry, 64, 654-657. http://dx.doi.org/10.1016/0022-3913(90)90290-S

[50] Wang, R.L., Moore, B.K., Goodacre, C.J., Swartz, M.L. and Andres, C.J. (1989) A Comparison of Resins for Fabricating Provisional Fixed Restorations. The International Journal of Prosthodontics, 2, 173-184.

[51] Osman, Y.I. and Owen, C.P. (1993) Flexural Strength of Provisional Restorative Materials. The Journal of Prosthetic Dentistry, 70, 94-96. http://dx.doi.org/10.1016/0022-3913(93)90038-P

[52] Ferracane, J.L., Condon, J.R. and Mitchem, J.C. (1992) Evaluation of Subsurface Defects Created during the Finishing of Composites. Journal of Dental Research, 71, 1628-1632. http://dx.doi.org/10.1177/00220345920710091601

[53] Drummond, J.L., Zhao, D. and Botsi,s J. (1995) Fracture Mechanisms of Dental Composites. In: Wise, D.L., Trantolo, D.J., Altobelli, D.E., Yaszemski, M.J., Gresser, J.D. and Schwartz, E.R., Eds., Encyclopedic Handbook of Biomaterials and Bioengineering, Marcel Dekker, New York, 1665-1696.

[54] McKinney, J.E. and Wu, W. (1982) Relationship between Subsurface Damage and Wear of Dental Restorative Composites. Journal of Dental Research, 61, 1083-1088. http://dx.doi.org/10.1177/00220345820610091101

[55] Lloyd, C.H. (1982) The Fracture Toughness of Dental Composites. II. The Environmental and Temperature Dependence of the Stress Intensification Factor (KIC). Journal of Oral Rehabilitation, 9, 133-138.

http://dx.doi.org/10.1111/j.1365-2842.1982.tb00543.x 